\title{
Apikal genital prolapsuslarda sakropeksi ve sakrospinöz ligaman fiksasyonu sonuçları
}

\section{Results of sacropexy and sacrospinous ligament fixation in apical genital prolapses}

\author{
Abdullah Boztosun*, Muradiye Yıldırım, Özlem Bozoklu Akkar, Asker Zeki Özsoy, \\ Gonca İmir Yenicesu, İptisam İpek Müderris, Ali Yanık
}

Kadın Doğum Anabilim Dalı (Yrd. Doç. Dr. A. Boztosun, Dr. M. Yıldırım, Yrd. Doç. Dr. Ö.B. Akkar, Doç. Dr. G. İ. Yenicesu, Prof. Dr. A. Yanık), Cumhuriyet Üniversitesi Tıp Fakültesi, TR58140 Sivas, Kadın Doğum Anabilim Dalı (Yrd. Doç. Dr. A.Z. Özsoy), Gaziosmanpaşa Üniversitesi Tıp Fakültesi, TR-60150 Tokat, Kadın Doğum Anabilim Dalı (Prof. Dr. İ. İ. Müderris), Erciyes Üniversitesi Tıp Fakültesi, TR-38039 Kayseri

\begin{abstract}
Özet
Amaç. Apikal genital prolapsus olgularının cerrahi tedavisinde uygulanan sakropeksi ve sakrosipinoz ligaman fiksasyonu operasyonlarının değerlendirilmesi. Yöntem. Uterin prolapsus veya vajen kaf prolapsusu nedeni ile opere edilen toplam 49 hastanın kayıtları retrospektif incelendi.Tüm hastaların sonuçları değerlendirildi, aynı zamanda sakropeksi (abdominal sakrokolpopeksi/sakroservikopeksi) ve sakrospinöz ligaman fiksasyon grupları oluşturularak değerlendirilme de yapıldı. Olgular postoperatif dönemdeki şikayetler, üriner inkontinans, hasta memnuniyeti ve postoperatif bulgular yönünden incelendi. Bulgular. Sakropeksi grubunda ortalama takip süresi 41,2 ay $(41,2 \pm 24,9)$, sakrospinöz fiksasyon grubunda ise 69,1 ay $(69,1 \pm 8,2)$ bulundu. Sakropeksi grubunda prolapsus nüksü tespit edilmedi. Sakrospinöz ligaman fiksasyon grubunda ise 2 olguda $(\% 11,1)$ nüks tespit edildi. Nüks açısından iki grup arasında anlamlı bir fark yoktu $(\mathrm{p}=0,058)$. Sakrospinöz fiksasyon grubunda sakropeksi grubuna göre anlamlı derecede daha yüksek oranda ön/arka onarım yapılmış olmasına rağmen $(\% 83,3$ 'e karşı, \%38,7, p=0,013) postoperatif tespit edilen sistorektosel bakımından iki grup arasında fark yoktu. Sakropeksi grubundaki hastaların \%93,5'i memnun, \%6,5'i orta düzeyde memnun iken, memnun olmayan hasta yoktu. Sakrosipinoz ligaman fiksasyon grubunda ise 2 olguda $(\% 11,1)$ memnuniyetsizlik mevcuttu. Hasta memnuyeti bakımından iki grup arasında anlamlı fark vard $1(p=0,034)$. Sonuç. Apikal genital prolapsus olguları için sakropeksi operasyonları ve sakrospinöz ligaman fiksasyonu operasyonunun yüzgüldürücü olduğu açıktır. Nüks ve hasta memnuniyeti yönünden, sakropeksi operasyonlarının daha yüz güldürücü olduğu söylenebilir. Sakropeksi opersyonları, sistorektosel operasyonu gereksinimini de azaltmaktadır.
\end{abstract}

Anahtar sözcükler: Sakropeksi, sakrokolpopeksi, sakroservikopeksi, sakrospinöz ligaman fiksasyonu

\begin{abstract}
Aim. Evaluation of sacropexy and sacrospinous ligament fixation operations that are applied in the surgical treatment of the cases of apical genital prolapses. Methods. The records of 49 patients who are operated for uterine prolapse or vaginal cuff prolapse were analysed retrospectively. The results of all patients were evaluated, and then the patients are allocated in two groups namely as sacropexy (abdominal sacrocolpopexy/sacrocervicopexy) and sacrospinous ligament fixation groups. Additionaly, the outcomes of groups were compared with each other. The cases were investigated specifically in terms of postoperative complaints, urinary incontinence, operation satisfaction, and postoperative signs. Results. Mean follow-up periods were 41.2 months (41.2 \pm 24.9$)$ in the sacropexy group, and 69.1 months $(69.1 \pm 8.2)$ in the sacrospinous fixation group. There weren't any cases of recurrent prolapse in the sacropexy group. Recurrence occured in two cases $(11.1 \%)$ in the sacrospinous ligament fixation group. There were no significant differences in recurrence rates between the two groups $(\mathrm{p}=0.058)$. Although anterior and posterior repair was more frequently applied in sacrospinous fixation group than sacropexy group (83.3\% vs. $38.7 \%$; $=0.013$ ), the rates of postoperatively detected cysto-rectocele were similar in both groups. While $93.5 \%$ of the patients in the sacropexy group were fully satisfied, and $6.5 \%$ of them
\end{abstract}


were moderately satisfied and there were no unsatisfied patients. In the sacrospinous ligament fixation group there were 2 unsatisfied patients $(11.1 \%)$. In terms of patient satisfaction there was significant difference between two groups $(\mathrm{p}=0.034)$. Conclusion. For cases of apical genital prolapse, sacropexy and sacrospinous ligament fixation operations are obviously promising. On the other hand, in terms of recurrence and patient satisfaction, sacropexy operations can be considered to be more promising. In addition, it can be said that sacropexy procedure can also reduce the need for the cystorectocele operation.

Keywords: Sacropexy, sacrocolpopexy, sacrocervicopexy, sacrospinous ligament fixation

Geliş tarihi/Received: 09 Nisan 2012; Kabul tarihi/Accepted: 16 Nisan 2012

\section{*İletişim adresi:}

Dr. Abdullah Boztosun, Kadın Doğum Anabilim Dalı, Cumhuriyet Üniversitesi Tıp Fakültesi, TR58140 Sivas. E-posta: abdullahboztosunyrd@hotmail.com

\section{Giriş}

Apikal pelvik organ prolapsusu (POP); vajinal apekse komşu olan yapıların aşağıya doğru yer değiştirmesidir. Küçük derecelerinde hastalar çoğunlukla "tuvalette elime bir şişlik geliyor" şeklinde tarif etmektedirler. Daha ileri derecelerinde ise, vajenden dışarı çıkarak aşikar hale gelebilmektedir. Doğum travması, artan yaş ve/veya postmenopozal dönem genital prolapsus gelişmesinde majör rol oynamaktadır [1]. Apikal genital proplapsus olguları her ne kadar ileri yaş hastalığı olsa da, reproduktif dönemdeki hastalar için de ciddi fiziksel ve psikososyal bir rahatsızlık sebebi olabilmektedir. Sakrospinöz fiksasyon ve sakrokolpopeksi operasyonları, literatürde bildirilen yüksek başarı oranları sebebiyle sık uygulanan cerrahi prosedürlerdir [2]. İlk olarak 1968' de Richter ve ark. [3] tarafindan tarif edilen sakrospinöz fiksasyon operasyonu, vajinal yaklaşımla uygulanmaktadır. 1962 'de Lane [4] tarafindan tanımlanan sakrokolpopeksi operasyonu ise, abdominal yolla uygulanmaktadır. Sakrokolpopeksi laparoskopik veya son zamanlarda giderek yaygınlaşan robotik yöntemler kullanılarak ta uygulanabilmektedir. Laparoskopik ve robotik sakrokolpopeksi uygulamalarının karşılaştırıldığ yapıldığı çalışmalar, son zamanlarda dikkat çekmektedir $[5,6]$.

$\mathrm{Bu}$ çalışmada, kliniğimizde yapılan sakropeksi ve sakrospinöz fiksasyon operasyonlarının sonuçlarının görülmesi ve bu sonuçların karşılaştırılması amaçlandı.

\section{Gereç ve yöntem}

Ocak 2006 -Nisan 2012 tarihleri arasinda POP nedeniyle opere edilen toplam 49 olgu çalışmaya dahil edildi. Hastalar, prolabe olan kısmın tespit edildiği yere göre; sakruma tespit uygulanan grup (sakropeksi grubu=SP) ve sakrospinöz ligamana tespit uygulanan grup (sakrospinöz fiksasyon grubu=SSF) olarak gruplandırıldı. SP grubundaki toplam 31 hastadan 24' üne sakrokolpopeksi, 7' sine sakroservikopeksi uygulandı. SSF grubunda 18 olgu mevcuttu. Çalışmamızda bu iki grup karşılaştırılmış olmakla birlikte 49 olgunun genel sonuçları da değerlendirildi. Tüm hastaların preoperatif ve postoperatif erken dönem bulgu, sonuç ve yapılan amelyat şekli retrospektif olarak hastane kayıtlarından tarand. Hastalar ile görüşülerek tekrar muayene edildi ve varsa yakınmaları değerlendirildi. İdrar inkontinansı ve memnuniyetleri ayrıntılı sorgulandı. Hastalarımızda disparoni sorgulanmak istendi ancak ileri yaş grubunda bu soruya cevap alınamamasi sebebi ile çalışmamızda değerlendirilmedi. Sakropeksi operasyonu genel anestezi altında, litotomi pozisyonunda, phannenstiel insizyonla gerçekleştirildi ve materyal olarak prolen mesh kullanıldı. Uterin prolapsusu bulunan ve menopoz dönemindeki hastalarda abdominal histerektomi uygulandıktan sonra, Y şeklinde hazırlanan prolen meshin kolları vajen ön ve arka duvarına 2/0 prolen sutürle 2-3 noktadan tespit edildi. Kaf prolapsusu bulunan olgularda ise vajen kafi adhezyonlardan diseke ve deperitonize edildikten sonra aynı işlem uygulandı. Reprodüktif dönemde bulunan 7 hastada ise aynı işlem her iki 
sakrouterin ligamentin servikal tutunma bölgelerine yakın yerden mesh kollarının tespiti ile yapıldı. Tüm olgularda Y mesh'in bacak kısmı 3. sakral vertebra ve promontorium arasında uygun bir alandan 2-3 cm'lik periton açıldıktan sonra anterior longitudunal ligamana 2-3 yerden 2/0 prolen sütür ile gerilimsiz tespit edildi. Bu sütürlerin longitudinal ligamandaki direnci her bir sütür için ayrı ayrı sütür geçildikten sonra 200-400 gr' lık bir kuvvet uygulanarak test edildi. Bu işlemler yapılırken mesh, douglası örten periton ya açılarak ya da tünel oluşturularak retroperitoneal alana yerleştirildi. Tüm olgularda Moskovich operasyonu ile douglas oblitere edildi. Sakrospinöz ligament fiksasyonunda ise genel anestezi altında, litotomi pozisyonunda vajen sağ tarafina insizyon yapılarak, rektovajinal boşluğa ulaşıldı. Sağ iskial spin künt diseksiyonla ortaya konarak sakrospinöz ligaman palpe edildi. İki adet tek sıfir emilemeyen suture, Deschamps sütür taşıyıcı yardımı ile sakrospinöz ligamandan geçirildi. Sütürlerin diğer uçları vajen apeksinden geçilerek vajen apeksi sakrospinöz ligamana tespit edildi.

\section{İstatistik}

Çalışmada elde edilen verilerin istatistiksel analizleri için SPSS (Statistical Package for Social Sciences) for Windows 15.0 programı kullanıldı. Çalışma verileri değerlendirilirken tanımlayıcı istatistiksel metodların (ortalama, standart sapma) yanısıra niceliksel verilerin karşılaştırılmasında Mann-Whitney $U$ test kullanıldı. Niteliksel verilerin karşılaştırılmasında ise Ki-Kare testi kullanıldı. Bunlara ek olarak tüm hastalarda hasta memnuniyeti ve diğer niteliksel veriler arasındaki ilişkiye Spearman korelasyon testi uygulandı. $\mathrm{p}<0,05$ düzeyinde anlamlı olarak değerlendirildi.

\section{Bulgular}

Hastaların yaşları 27 ile 87 arasında, gravidite ve pariteleri 1 ile 14 arasında değişmekteydi. POP-Q derecesi 3'ten küçük olgu yoktu. SP grubunda 10 (\%32) olgu reproduktif dönemde, 21 (\%68) olgu menopoz döneminde, SSF grubunda ise $8(\% 44)$ olgu reproduktif dönemde, 10 (\%56) olgu menopoz döneminde olup iki grup arasında istatistiksel olarak anlamlı fark yoktu $(\mathrm{p}<0,05)$. Grupların genel özellikleri Tablo1' de verildi. İki grup arasında sadece hasta takip süreleri bakımından istatistiksel olarak anlamlı farklılık vardı $(\mathrm{p}<0,001)$. SSF grubunun takip süreleri daha uzun idi. Bunun sebebi, sakropeksi operasyonlarının son zamanlarda daha çok uygulanması ve yaklaşık 42 aydır sakrospinöz fiksasyon uygulanan hastamızın olmayışıdır. SP grubunda vajen kaf prolapsusu nedeniyle 8 olguya $(\% 25,8)$, desensus uteri nedeniyle 23 olguya $(\% 74,2)$ abdominal sakropeksi uyguland. SSF grubunda ise vajen kaf prolapsusu nedeniyle 5 olguya $(\% 27,8)$, desensus uteri nedeniyle $13(\% 72,2)$ olguya sakrospinöz fiksasyon uyguland1. Prolapsus şekli bakımından iki grup arasında istatistiksel fark yoktu $(\mathrm{p}=0,880)$. Olgulara eş zamanlı histerektomi, ön onarım ve/veya arka onarım ve anti inkontinans prosedürü uygulanıp uygulanmadığı ve operasyon öncesi ve sonrasında idrar kaçırma ve takipte, sistosel ve/veya rektosel mevcudiyeti Tablo 2'de gösterildi. SP grubunda postoperatif takipte 3 olguda sistosel, 2 olguda rektosel mevcut iken SSF grubunda 4 olguda sistosel, 1olguda rektosel ve 2 olguda sistorektosel tespit edildi. 2. dereceden büyük sistosel ve/ veya rektosel mevcut değildi ve gruplar arasında fark yoktu. Olgular eş zamanlı üriner anti-inkontinans prosedür ve histerektomi uygulanması ve postoperatif inkontinans mevcudiyeti bakımından değerlendirildiğinde de iki grup arasında fark tespit edilmedi $(\mathrm{p}<0,05)$.

Tablo 1. Grupların genel özellikleri.

\begin{tabular}{llllll}
\hline Grup & \multicolumn{6}{l}{ Sakropeksi $\mathbf{n = 3 1}$} & \multicolumn{3}{l}{ Sakrospinöz fiksasyon n=18 } \\
& Min-Max & ortalama \pm SS & Min-Max & ortalama \pm SD & p değeri \\
\hline yaş & $27-87$ & $56,4 \pm 16,0$ & $40-76$ & $58,5 \pm 12,8$ & 0,72 \\
gravidite & $1-14$ & $5,8 \pm 3,3$ & $2-14$ & $7,1 \pm 3,4$ & 0,21 \\
parite & $1-14$ & $5,2 \pm 3,1$ & $2-11$ & $5,7 \pm 2,4$ & 0,35 \\
Pop-Q (derece) & $3-4$ & $3,5 \pm 0,5$ & $3-4$ & $3,5 \pm 05$ & 0,79 \\
Takip (ay) & $6-74$ & $41,2 \pm 24,9$ & $42-75$ & $69,1 \pm 8,2$ & $<0,001^{*}$ \\
\hline
\end{tabular}

*İstatistiksel anlamlı, POP-Q: Pelvik organ prolapsus derecesi 
Tablo 2. Gruplarda ek operasyonlar ve takipteki bulgular.

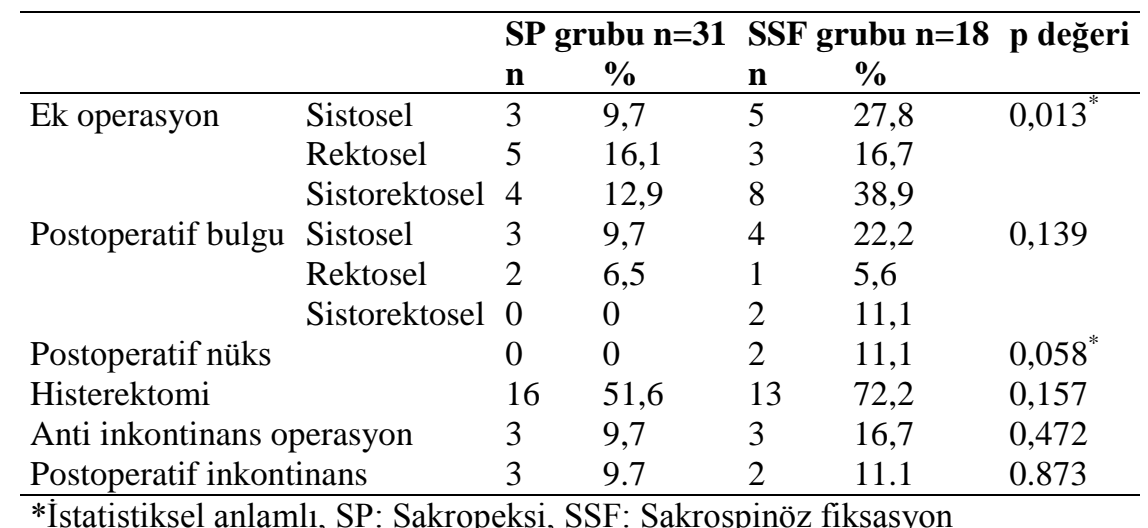

*İstatistiksel anlamlı, SP: Sakropeksi, SSF: Sakrospinöz fiksasyon

SP grubunda ki hastaların \%100 memnuniyeti mevcut iken SSF grubunda bu oran \% 88,9 olarak bulundu. Hastaların memnuniyetleri ve postoperatif ağrı şikayetleri tablo 3 ' de ve hasta memnuyeti ile ilişkili paremetrelerin korelasyon analizi tablo 4'te verildi.

Tablo 3. Gruplarda hasta memnuyeti ve ağrı şikayetleri.

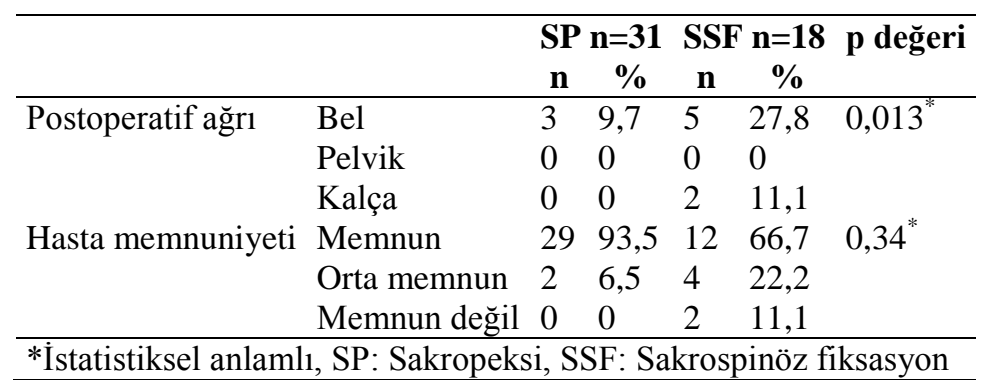

Tablo 4. Hasta memnuniyeti ve ilişkili parametreler arasındaki korelasyon.

\begin{tabular}{lll}
\hline & r & p değeri \\
\hline Ameliyat tipi & 0.359 & $0.011^{*}{ }^{*}$ \\
Postop nüks & 0.534 & $<0.001^{*}$ \\
Postop sistorektosel & 0.556 & $<0.001^{*}$ \\
Postop inkontinans & 0.230 & 0.112 \\
Postoperatif ağrı & 0.875 & $<0.001^{*}$ \\
Antiinkontinans prosedür & -0.165 & 0.259 \\
\hline
\end{tabular}

*İstatistiksel anlamlı

Bu bulgulara ek olarak postoperatif SP grubunda 3, SSF grubunda 2 hastamızda kab1zl1k mevcuttu. Diğer taraftan SP grubunda 2 hastamızda ameliyat öncesi idrar yapamama şikayeti mevcuttu. Bunlardan bir tanesinde obstrüktif nefropati gelişmek üzere idi ve bilateral nefrostomi kateteri mevcuttu. Abdominal sakrokolpopeksi sonrasinda nefropati düzeldi ve nefrostomi kateterleri çekildi.

\section{Tartışma}

Bu çalışmada sakropeksi operasyonlarının vajen kaf prolapsusu veya uterin prolapsuslar için etkili olduğu gösterildi. Sakrospinöz fiksasyona göre sakropeksi operasyonlarında, intraoperatif ek operasyon yapılma oran1, prolapsus nüksü oranı ve postoperatif ağrı oranlarının daha az, buna karşın hasta memnuniyetinin ise daha fazla olduğu görüldü. Bu farkların oluşmasında iki grup arasındaki takip sürelerinin farklı olması sonuçlarımızı etkileyecek faktörlerden biri olabilir. Ancak SSF grubundaki nükslerin zaten 8 aydan önce olduğu da dikkate alınmalıdır. Literatürde de, bizim bulgularımız ile uyumlu olarak sakrospinöz fiksasyon sonrası nükslerin erken dönemde olduğuna dikkat çekilmiştir [7]. Bunlara ek olarak SP grubunda 8 aydan az takip edilen sadece 3 olgu mevcut ve en kisa takip süresi 6 ay idi. Biz nüks oranlarımızın düşüklügünü ve ek olarak ön arka onarım yapılmasına az ihtiyaç duymamızı cerrahi tekniğimize bağlıyoruz. Jeon ve ark. [8] 
abdominal sakrokolpopeksili 57 olgunun ortalama 66 aylık takip sonuçlarını verdikleri çalışmalarında POP-Q (Pelvik organ prolapsus sınıflaması) derecesi 2 ve üzerinde apikal nüks olgusu olmadığını belirtmişlerdir. Tarif ettikleri cerrahi teknik bizimkine benzemektedir. Diğer taraftan biz anterior longitudunal ligamandan geçilen süturlerin belli bir kuvvetle test edilmesi ve sağlamlığından emin olunmasının şart olduğuna inanıyoruz. Misrai ve ark. [9] 43 olguda laparoskopik sakrokolpopeksi sonrasında apikal prolapsus olmadığını, diğer yandan sistoseli düzeltmedeki başarı oranlarının \%84 olduğunu bildirmişlerdir. Çalışmamızda bu oranı \%87 olarak bulduk. Sonuçlarımız bu çalışma ile de benzerdir. Vajinal yaklaşımla sakrospinoz fiksasyon, medikal kapasitesi sınırlı hastalarda, hızlı iyileşme isteği olan hastalarda, ileri derecede rektoseli olan veya vajinal anti-inkontinans prosedürlerinin de planlandığı hastalarda tercih edilebilir. Medikal kapasitesi sinırlı hastalarda lokal anestezi ile de yapılabilen kolpokleizis daha iyi bir seçenek olabilir. Ön-arka onarım abdominal sakrokolpopeksi ile birlikte de uygulanabilir. Abdominal sakrokolpopeksi ile birlikte anti inkontinans prosedürlerinin uygulanması ise tartışmalı bir konudur. POP olgularının \%15-80'inde stres inkontinans (SI) görülebilmektedir [10]. Ancak prolapsus için yapılan operasyon sonrası Sİ düzelebilmektedir. Diğer taraftan POP cerrahisi gizli olan Sİ'ın ortaya çıkmasına da sebeb olabilmektedir. Bunlara ek olarak POP'lu hastalarda gizli Sİ'nın preoperatif teşhisi de zor olabilmektedir. Bu konuda preoperatif ürodinami incelemesi, redüksiyon stres test veya postoperatif öksürük stres test gibi yöntemler önerilmektedir [11-13]. Vajinal pesser ile yapılan redüksiyon stres testte \%67 duyarlılık bildirilmektedir [14]. Burada diğer bir zorlukta ileri yaşlardaki hastaların bu testlere uyumudur. Abdominal sakrokolpopeksi ile eş zamanlı profilaktik anti-inkontinans operasyon yapılmasının postop inkontinansı azalttığ bildirilse de bunun tam tersini bildiren çalışmalarda mevcuttur [15, 16]. Bunlaraa ek olarak abdominal sakrokolpopeksi ile birlikte yapılacak burch operasyonunun rektosel gelişimini veya rekürrensi artırdığı da bildirilmektedir [17]. Son zamanlarda yapılan çalışmalar, SUI olmayan hastalara anti-inkontinans cerrahisi uygulanmaması gerektiğini ve hatta redüksiyon stres testin pozitif olduğu POP'lu hastalarda da iki aşamalı cerrahi yaklaşımın uygun olacağını önermektedir [11]. Biz de bu uygulamanın doğru olduğunu düşünmekteyiz. Kliniğimizde abdominal sakrokolpopeksi ile birlikte profilaktik antiinkontinans prosedürü uygulanmamaktadır. Nitekim çalışmamızda hasta memnuniyeti ile postoperatif inkontinans varlığı veya anti-inkontinans prosedür uygulanmasının anlamlı bir ilişkisi tespit edilmedi. Ülkemiz şartlarında POP'lu hastaların hemen hepsi aşikar veya elle hissedilen şişlik şikayeti ile jinekologa başvurmaktadır. Hatta bu durumda bile birkaç yıl geçirmiş, idare etmiş ve de bir olgumuzda olduğu gibi obstrüktif nefropati teşhisi sonrası hekim önerisi ile jinekoloğa gelmiştir.

Sonuç olarak, hasta memnuniyetini etkileyebilecek faktörlerin hasta memnuniyeti ile korelasyonları incelendiğinde; en kuvvetli ve negatif yönlü korelasyonun postoperatif ağrı ile olduğu görüldü. Bunu sistorektosel mevcudiyeti ve nüks mevcudiyeti takip etmektedir. Yapılan amelyat tipi de hasta memnuniyeti ile zayıf ancak anlamlı bir ilişki göstermektedir. Apikal genital prolapsuslarda öncelikli hedefin vajen kafı veya uterusun normal anatomik pozisyonda sabitlenmesi olması gerektiği aşikardır. Hasta memnuniyeti için postoperatif ağrının olmadığı, hastanın öncelikli şikayetlerinin ortadan kaldırıldığı ve nükslerin görülmediği uygun operasyon tercih edilmelidir. Anti-inkontinans prosedürlerin genç ve operasyon beklentileri fazla olan ve redüksiyon stres testin pozitif olduğu hastalarda düşünülmesi ve hasta ile görüşülerek ikinci bir operasyon seçeneği olarak sonradan değerlendirilmesinin daha doğru olabileceği ayrıntılı anlatılmalıdır. Hasta ile iletişimin zor olduğu ileri yaşlardaki hastalar için bu durumlar hasta yakınlarına da ayrıntılı anlatılarak karşılaşılabilecek hukuki sıkıntılar asgari düzeye indirilmeye çalışılmalıdır. 


\section{Kaynaklar}

1. DeLancey JOL. Anatomy and biomechanics of genital prolapse. Clin Obstet Gynecol 1993; 36: 897-909.

2. Uzoma A, Farag KA. Vaginal vault prolapse. Obstet Gynecol Int 2009; 275621.

3. Richter K. The surgical anatomy of the vaginaefixatio sacrospinalis vaginalis. A contribution to the surgical treatment of vaginal blind pouch prolapse. Geburtshilfe Frauenheilkd 1968; 28: 321-7.

4. Lane FE. Repair of posthysterectomy vaginal-vault prolapse. Obstet Gynecol 1962; 20: 72-7.

5. Paraiso MF, Jelovsek JE, Frick A, Chen CC, Barber MD. Laparoscopic compared with robotic sacrocolpopexy for vaginal prolapse: a randomized controlled trial. Obstet Gynecol 2011; 118: 1005-13.

6. Judd JP, Siddiqui NY, Barnett JC, Visco AG, Havrilesky LJ, Wu JM. Costminimization analysis of robotic-assisted, laparoscopic, and abdominal sacrocolpopexy. J Minim Invasive Gynecol 2010; 17: 493-9.

7. Benson JT, Lucente V, McClellan E. Vaginal versus abdominal reconstructive surgery for the treatment of pelvic support defects: a prospective randomized study with long-term outcome evaluation. Am J Obstet Gynecol 1996; 175: 141821. discussion 1421-2.

8. Jeon MJ, Moon YJ, Jung HJ, Lim KJ, Yang HI, Kim SK, Bai SW. A long-term treatment outcome of abdominal sacrocolpopexy. Yonsei Med J 2009; 50: 80713.

9. Misraï V, Rouprêt M, Seringe E, Vaessen C, Cour F, Haertig A, Richard F, Chartier-Kastler E. Long-term results of laparoscopic sacral colpopexy for highgrade cystoceles. Prog Urol 2008; 18: 1068-74.

10. Bai SW, Jeon MJ, Kim JY, Chung KA, Kim SK, Park KH. Relationship between stress urinary incontinence and pelvic organ prolapse. Int Urogynecol J Pelvic Floor Dysfunct 2002; 13: 256-60.

11. Elser DM, Moen MD, Stanford EJ, Keil K, Matthews CA, Kohli N, Mattox F, Tomezsko J; Urogynecology Network. Abdominal sacrocolpopexy and urinary incontinence: surgical planning based on urodynamics. Am J Obstet Gynecol 2010; 202: 375.e1-5.

12. Visco AG, Brubaker L, Nygaard I, Richter HE, Cundiff G, Fine P, Zyczynski H, Brown MB, Weber AM; Pelvic Floor Disorders Network. The role of preoperative urodynamic testing in stress-continent women undergoing sacrocolpopexy: the Colpopexy and Urinary Reduction Efforts (CARE) randomized surgical trial. Int Urogynecol J Pelvic Floor Dysfunct 2008; 19: 60714.

13. Fatton B, Dwyer PL, Achtari C, Tan PK. Bilateral extraperitoneal uterosacral vaginal vault suspension: a 2-year follow-up longitudinal case series of 123 patients. Int Urogynecol J Pelvic Floor Dysfunct 2009; 20: 427-34.

14. Srikrishna S, Robinson D, Cardozo L. Ringing the changes in evaluation of urogenital prolapse. Int Urogynecol J 2011; 22: 171-5.

15. Brubaker L, Cundiff GW, Fine P, Nygaard I, Richter HE, Visco AG, Zyczynski H, Brown MB, Weber AM; Pelvic Floor Disorders Network. Abdominal sacrocolpopexy with Burch colposuspension to reduce urinary stress incontinence. N Engl J Med 2006; 354: 1557-66.

16. Costantini E, Zucchi A, Giannantoni A, Mearini L, Bini V, Porena M. Must colposuspension be associated with sacropexy to prevent postoperative urinary incontinence? Eur Urol 2007; 51: 788-94.

17. Gadonneix P, Ercoli A, Salet-Lizée D, Cotelle O, Bolner B, Van Den Akker M, Villet R. Laparoscopic sacrocolpopexy with two separate meshes along the anterior and posterior vaginal walls for multicompartment pelvic organ prolapse. J Am Assoc Gynecol Laparosc 2004; 11: 29-35. 